\title{
Conhecimento e atitudes de pediatras em relação à cárie dentária*
}

Vanessa Dalto ${ }^{1}$

Barbara Turini ${ }^{2}$ Luiz Cordoni Junior ${ }^{3}$

\section{Introdução}

Atualmente, os profissionais de Odontologia buscam promover saúde bucal por meio da atenção precoce, uma vez que valores e atitudes adquiridos durante os primeiros anos de vida ficam fortemente resistentes a mudanças e se tornam hábitos rotineiros (Faria, Oliveira, Pordeus, 1997).

Neste contexto, vários fatores colocam o pediatra em uma posição privilegiada no contato com a criança e seus responsáveis. Em geral, ele é o primeiro profissional da área da saúde a se relacionar com a criança e sua família, possui maior contato com os mesmos durante os primeiros anos de vida de seu paciente, e tem a confiança e receptividade dos pais em suas palavras e orientações (Schalka \& Valente, 2002; Barroso, Miasato, Graça, 2001; Nowak et al., 1994 apud Pastor \& Rocha, 2001; Freire, Macedo, Silva, 2000).

Portanto, tendo em vista o bem-estar do indivíduo, e particularmente a saúde integral da criança, sem a setorizar, torna-se evidente a importância da interdisciplinaridade entre a Pediatria Médica e a Odontológica (Pastor \& Rocha, 2001).

O objetivo deste estudo consistiu em verificar o conhecimento e atitudes de médicos pediatras atuantes na cidade de Londrina, PR frente a aspectos odontológicos relacionados à promoção de saúde bucal das crianças por eles atendidas.

\section{Metodologia}

População estudada: o estudo foi realizado com médicos pediatras atuantes na rede pública de saúde e clínicas e hospitais particulares da cidade de Londrina, PR. Uma vez que o site do Conselho Regional de Medicina não disponibiliza uma lista dos médicos pediatras cadastrados atuantes em Londrina-PR, optou-se por obter a relação dos profissionais por meio do site da Associação Médica de Londrina ( $\mathrm{AML})$, bem como de listas telefônicas da região. Os nomes de profissionais atuantes em Unidades Básicas de Saúde do município foram conseguidos mediante contato telefônico com as unidades. Da relação assim

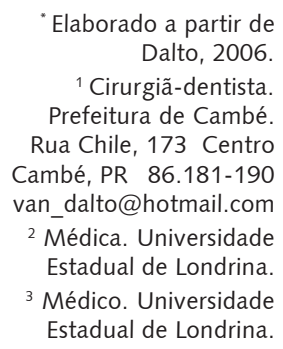
Dalto, 2006.

${ }^{1}$ Cirurgiã-dentista. Prefeitura de Cambé. Rua Chile, 173 Centro Cambé, PR 86.181-190 van_dalto@hotmail.com ${ }^{2}$ Médica. Universidade Estadual de Londrina. ${ }^{3}$ Médico. Universidade Estadual de Londrina. 
obtida, foram utilizados os seguintes critérios de exclusão: não-médicos, não-pediatras e pediatras não atuando na prática clínica.

Coleta de dados: antecedendo o estudo principal, efetuou-se pré-teste com pediatras de cidade vizinha, objetivando testar a técnica metodológica e a validade do método de coleta de dados. Para a realização da pesquisa, foi enviado, pelo correio, questionário aos profissionais, para levantamento de seu conhecimento sobre a formação e desenvolvimento dos dentes e doença cárie. Anexado ao questionário, foram enviados, ainda, carta de apresentação, orientando quanto ao objetivo da pesquisa, garantia de anonimato e demais aspectos éticos, e Termo de Consentimento Livre e Esclarecido. Os questionários foram recolhidos pessoalmente, num primeiro momento, após quinze dias transcorridos da data de envio aos médicos. Uma segunda coleta foi realizada após quinze dias da primeira, a fim de se evitar perdas em excesso e o comprometimento da pesquisa.

Análise dos dados: os dados obtidos foram processados e analisados em programa eletrônico Epi Info versão 3.3.2 para Windows. Realizou-se análise quantitativa, com distribuição de freqüência das respostas mencionadas. Questões nas quais houve múltiplas escolhas onde somente caberia uma resposta foram desconsideradas. Os resultados obtidos foram comparados com resultados divulgados em estudos semelhantes.

Aspectos éticos: o presente estudo foi submetido e aprovado pelo Comitê de Ética em Pesquisa da Universidade Estadual de Londrina (parecer 170/05 de 15 de agosto de 2005) e pela Autarquia Municipal de Saúde de Londrina (C.P./029/05/Gecape), para inclusão dos profissionais da rede municipal de saúde.

\section{Resultados}

Perfil da população: foi obtida uma lista contendo 98 nomes diferentes de profissionais. Destes, foram excluídos 11, de acordo com os critérios descritos anteriormente, resultando em um total final de 87 pediatras. Conseguiu-se um retorno de 52 médicos (59,8\%), dos quais $57,7 \%$ correspondiam ao sexo feminino. A média de idade entre os 48 pesquisados que responderam a este item foi de 46,0 anos, variando de 28 a 75 anos; $86,5 \%(n=45)$ estavam formados há mais de 10 anos, e $75,0 \%(n=39)$ trabalhavam em, pelo menos, um local pertencente à rede pública de saúde. Quando questionados sobre o fato de terem recebido instruções sobre saúde bucal em crianças, $71,2 \%(n=37)$ responderam afirmativamente. Destes, o momento mais freqüentemente mencionado foi durante a residência médica $(56,8 \%)$, seguida por $37,8 \%$ que citaram a participação em cursos, e $29,7 \%$ que mencionaram a graduação. Todos os pediatras participantes do estudo responderam ter como rotina avaliar a cavidade bucal das crianças, sendo que $86,5 \%(n=45)$ realizam o exame em todas as consultas. Quase todos os médicos avaliam amígdalas e palato mole, dentes, língua e higiene bucal. Em menor freqüência, foram mencionados aspectos ortodônticos e alterações em tecido mole.

Formação dos dentes: a grande maioria, 94,2\% ( $n=49)$ e 90,4\% $(n=47)$, informou conhecer a época de formação dos dentes decíduos e permanentes, respectivamente. Quanto à existência de medicamentos que interferem na formação dos dentes, todos os 48 médicos que responderam à questão concordaram com a existência de tais drogas. A tetraciclina foi a substância mais citada $(68,8 \% ; n=33)$ por esses profissionais, seguida por $14,6 \%(n=7)$ que mencionaram antibióticos, sem especificação da substância ativa. Flúor foi citado por apenas dois profissionais. Em relação a doenças, 44 pediatras responderam à questão, afirmando a possibilidade de alterações na formação dos dentes em decorrência de processos patológicos. Tais profissionais indicaram, com maior freqüência, infecções ou processos infecciosos $(38,6 \% ; n=17)$. Alterações genéticas ou embrionárias e carências nutricionais foram mencionadas em menor freqüência.

Cárie dentária: sobre a doença, $28,8 \%(n=15)$ dos pediatras não informaram qual sua etiologia. Em $61,5 \%(n=32)$ dos questionários, o fator bacteriano foi citado como tendo envolvimento na etiologia da cárie dentária, sendo que em $38,5 \%(n=20)$, as bactérias foram mencionadas como causa única da doença. Menos da metade dos profissionais $(48,1 \% ; n=25)$ 
concordaram com a característica de transmissibilidade da cárie dentária, contudo, a maior parte $(73,1 \% ; n=38)$ afirmava tratar-se de doença infecciosa. Houve dúvidas em relação à cariogenicidade do leite materno, pois a freqüência de respostas negativas foi de 51,9\% ( $n=27)$ contra $48,1 \%(n=25)$, afirmando ser o leite materno cariogênico; $96,2 \%(n=50)$ assinalaram que conhecem o termo "cárie de mamadeira". Para 21,2\% ( $n=11)$, os antibióticos podem causar cáries, sendo que, dos pediatras que afirmaram a sua não cariogenicidade, quatro ressaltaram ser o veículo açucarado dos antibióticos, e não seu princípio ativo, o responsável pela instalação de lesões cariosas.

\section{Discussão}

Embora o percentual de profissionais que receberam instrução sobre saúde bucal em crianças tenha sido alto, não deve ser desconsiderado que 15 médicos nunca tiveram tal informação. Segundo Maltz e Lacerda (2001), a cavidade bucal é excluída, pela Medicina, de sua área de competência, especialmente quando são consideradas as suas doenças de maior prevalência, como a cárie e a doença periodontal. Dessa forma, áreas em que a integração médico-odontológica é indispensável, como a Pediatria, são prejudicadas, resultando em cuidados deficientes em relação à saúde oral (Maltz \& Lacerda, 2001; Pastor \& Rocha, 2001).

Ao contrário de investigações divulgadas em outras publicações, neste estudo a residência médica foi a fonte de informações sobre saúde bucal em crianças mais freqüentemente mencionada pelos pediatras $(56,8 \%)$. Em estudo realizado por Freire, Macedo e Silva (2000), a graduação aparece em primeiro lugar $(38,5 \%)$, seguida por cursos de reciclagem não promovidos pelo Sistema Único de Saúde $(28,1 \%)$ e residência pediátrica $(24,0 \%)$. Cursos extracurriculares $(22,9 \%)$ foram a principal fonte de informações sobre odontologia preventiva entre os profissionais pesquisados por Schalka e Rodrigues (1996), seguidos de residência pediátrica $(20,8 \%$ ) e graduação (14,5\%). Em levantamento realizado por Campos et al. (2003), apenas 33\% dos pediatras estudaram a etiologia da cárie dentária durante o curso de Medicina. Os resultados acima sugerem que muitos pediatras buscam melhorar seu conhecimento sobre o assunto por intermédio da participação em cursos, tornando este meio de transmissão importante para a divulgação de novas informações e reforço de determinadas práticas. Em Londrina - PR, cursos de capacitação e fóruns promovidos pela Secretaria Municipal de Saúde podem ser fontes de informações muito utilizadas pelos profissionais pesquisados, uma vez que grande número deles $(75,0 \%)$ trabalha em locais ligados ao sistema público de saúde.

Com relação à formação dos dentes, Maltz \& Lacerda (2001) encontraram valores menores entre os pediatras por elas estudados: $56,47 \%$ não souberam informar com que idade a mesma se completa; $35,59 \%$ não relataram a tetraciclina como sendo prejudicial durante este período, e apenas dois de 85 médicos indicaram o flúor como substância nociva durante a formação dos dentes. O conhecimento sobre tal questão é valioso para que possa ser evitada a prescrição de medicamentos prejudiciais em função da idade da criança, assim como também suspeitar de alterações sistêmicas em decorrência da presença de modificações nos dentes. Na presente pesquisa, deve ser ressaltada a pequena porcentagem de pediatras que relatou o flúor como sendo prejudicial durante este período, devido ao risco de fluorose dentária em conseqüência do uso abusivo desta substância.

Cárie dentária é, provavelmente, a doença da cavidade bucal mais conhecida entre as pessoas. Sua etiologia é multifatorial, envolvendo hospedeiro, microbiota e substrato ou dieta, que precisam interagir por determinado tempo (Newbrun, 1988). É considerada doença infecciosa, de origem bacteriana e com características de transmissibilidade (Guedes-Pinto, 2003; Kriger, 1997; Walter, Ferelle, Issao, 1997). Entretanto, menos da metade dos profissionais que participaram da pesquisa $(48,1 \%)$ assinalaram que a cárie dentária é transmissível, apesar de grande parte $(73,1 \%)$ declarar se tratar de doença infecciosa. Em estudo realizado por Figueiredo, Palmini e Rodrigues (1997), somente $27 \%$ dos profissionais pesquisados afirmaram a transmissibilidade e $85 \%$ que é doença infecciosa.

A aquisição de bactérias cariogênicas pelos bebês se faz pelo contato da criança com o ambiente familiar, sendo as mães, possivelmente, as maiores fontes de contaminação (Guedes-Pinto, 2003). 
Uso de talheres, soprar a comida para esfriar, beijos nos lábios e uso em comum de escovas são algumas atitudes que possibilitam infecção (Guedes-Pinto, 2003; Kriger, 1997). Sabe-se que, quanto mais precoce for a colonização bacteriana, maior será o risco de desenvolver lesões de cáries (Walter, Ferelle, Issao, 1997). Portanto, os pais devem ser alertados quanto às vias de infecção, para que práticas que possibilitem a transmissão de microrganismos cariogênicos sejam evitadas (Schalka \& Valente, 2002). No estudo de Freire, Macedo e Silva (2000), o fator bacteriano foi o mais comumente associado à doença cárie: $46,9 \%$ dos pediatras apontaram fatores bacterianos e dietéticos, e $28,1 \%$ apenas os fatores bacterianos. Os profissionais do atual estudo também relacionaram fortemente a ação de fatores bacterianos na instalação da doença: $61,5 \%$ referiram-se ao papel das bactérias no processo. Contudo, as informações apresentadas pelos pediatras sobre a etiologia da cárie dentária estão incompletas, pois, apesar de se tratar de doença multifatorial, o papel dos outros fatores etiológicos não foi destacado pela maioria dos profissionais.

Também em relação à cárie dentária, deve-se ressaltar que pouco mais de $20 \%$ dos pediatras acreditam que antibióticos podem causar cáries, enquanto em pesquisa realizada por Paiva, Bezerra e Toledo (1990) apenas $8 \%$ dos profissionais informaram que os mesmos aumentam o risco de cárie dentária. Os autores lembram que, em relação à administração de medicamentos para crianças, a cariogenicidade está relacionada ao açúcar presente em seu veículo, fato ressaltado por quatro pediatras da atual pesquisa.

A cariogenicidade do leite materno ainda é um ponto que precisa ser esclarecido para os pediatras participantes do presente estudo: apenas $48,1 \%$ afirmaram que o leite materno pode causar cáries. Na pesquisa de Campos et al. (2003), somente $16 \%$ dos médicos concordaram com a questão da cariogenicidade. Considera-se, atualmente, que, em condições normais de ingesta, o potencial cariogênico do leite materno é de pouco significado clínico (Kriger, 1997). Porém, quando o consumo é realizado em grande freqüência e em situações em que os fatores protetores salivares não estão presentes, como durante o sono, o leite materno é tão ou mais cariogênico que outros alimentos contendo açúcares (Guedes-Pinto, 2003; Kriger, 1997; Walter, Ferelle, Issao, 1997).

\section{Considerações finais}

Os resultados aqui observados indicam que os médicos pediatras atuantes em Londrina - PR têm bons conhecimentos e apresentam atitudes positivas em relação à saúde bucal de seus pacientes. Deve ser levado em consideração, ainda, que discrepâncias de resultados encontrados neste estudo e em pesquisas semelhantes aqui mencionadas podem também estar relacionadas às diferenças de épocas em que as observações foram realizadas. Ainda é necessário ampliar e reforçar conhecimentos a respeito de prevenção em saúde bucal, sobretudo aspectos relacionados à etiologia da cárie dentária. Uma avaliação mais sistemática da situação é indispensável para se identificarem as reais carências tanto de médicos pediatras quanto de odontopediatras, para que possíveis deficiências no ensino da Pediatria possam ser sanadas e as crianças tenham maiores chances de se desenvolverem em boas condições de saúde geral e bucal. A atualização dos profissionais e a compreensão da importância de um atendimento interdisciplinar e multiprofissional são fundamentais para o tratamento do paciente como um todo.

\section{Colaboradores}

Os autores Vanessa Dalto e Barbara Turini participaram, igualmente, da elaboração do artigo, de sua discussão, redação e da revisão do texto. Luiz Cordoni Junior participou de discussões e revisão do texto. 


\section{Referências}

BARROSO, S.P.; MIASATO, J.M.; GRAÇA, T.C.A. Avaliação da freqüência de visitas ao pediatra $x$ visitas ao odontopediatra em unidade básica de saúde do município de Niterói-RJ. 15 out. 2001. Disponível em: <http://www.odontologia.com.br/artigos. asp?id=236>. Acesso em: 18 jun. 2005.

CAMPOS, S. F. F. et al. Conhecimento de médicos pediatras e ginecologistas/obstetras sobre prevenção em odontologia para gestantes. Rev. Odontol. UNICID, v.15, n.3, p.173-82, 2003.

DALTO, V. Conhecimento e atitudes de pediatras de Londrina - PR em relação à promoção de saúde bucal. 2006. Monografia (Especialização em Saúde Coletiva) Departamento de Saúde Coletiva, Universidade Estadual de Londrina, Londrina. 2006.

FARIA, C.F.; OLIVEIRA, C.M.R.; PORDEUS, I.A. Avaliação de conhecimento e atitudes relacionados à prevenção em odontopediatria: um estudo com gestantes, mães e profissionais da área médica. Arq. Odontol., v.33, n.2, p.121-32, 1997.

FIGUEIREDO, M.C.; PALMINI, A.L.; RODRIGUES, R.M.A. A importância da interação pediatra-odontopediatra no atendimento integral a crianças. Rev. Fac. Odontol. Univ. Passo Fundo, v.2, n.2, p.11-8, 1997.

FREIRE, M.C.M.; MACÊDO, R.A.; SILVA, W.H. Conhecimentos, atitudes e práticas dos médicos pediatras em relação à saúde bucal. Pesqui. Odontol. Bras., v.14, n.1, p.3945, 2000.

GUEDES-PINTO, A.C. Odontopediatria. 7.ed. São Paulo: Santos, 2003.

KRIGER, L. (Coord.). ABOPREV: promoção de saúde bucal. São Paulo: Artes Médicas, 1997.

MALTZ, M.; LACERDA, P. Conhecimento do pediatra na área da saúde bucal. Rev. ABO Nac., v.9, n.4, p.210-6, 2001.

NEWBRUN, E. Cariologia. 2.ed. São Paulo: Santos, 1988.

PAIVA, M.S.; BEZERRA, V.L.V.A.; TOLEDO, O.A. O pediatra e a saúde oral da criança. RGO, v.38, n.2, p.96-100, 1990.

PASTOR, I.M.O.; ROCHA, M.C.B.S. Integração da pediatria médica e odontológica na promoção da saúde: enfoque funcional do sistema estomatognático. Rev. Fac.

Odontol. Univers. Fed. Bahia, v.23, p.74-80, 2001.

SCHALKA, M.M.S.; RODRIGUES, C.R.M.D. A importância do médico pediatra na promoção da saúde bucal. Rev. Saúde Pública, v.30, n.2, p.179-86, 1996.

SCHALKA, M.M.S.; VALENTE, M.H. Promoção de saúde bucal. In: ISSLER, H.; LEONE, C.; MARCONDES, E. (Coords.). Pediatria na atenção primária. São Paulo: Sarvier, 2002. p.115-29.

WALTER, L.R.F.; FERELLE, A.; ISSAO, M. Odontologia para o bebê: odontopediatria do nascimento aos três anos. São Paulo: Artes Médicas, 1997. 
Atualmente a atenção odontológica precoce tem sido enfatizada, pois atitudes e práticas adquiridas nos primeiros anos de vida tornam-se resistentes a mudanças. Devido ao maior contato com seus pacientes, o pediatra é profissional importante na transmissão de orientações relacionadas à saúde bucal. O presente estudo teve como objetivo verificar conhecimentos e atitudes de médicos pediatras atuantes em Londrina - PR, em relação à promoção de saúde bucal de crianças por eles atendidas. Dados foram coletados mediante questionário, abordando aspectos referentes à formação dos dentes e doença cárie. Sobre a cárie dentária, 28,8\% dos pediatras não informaram qual sua etiologia, enquanto $48,1 \%$ afirmaram a transmissibilidade da doença. Os resultados observados sugerem que os pediatras apresentam atitudes e práticas positivas em relação à saúde bucal, mas que informações sobre cárie dentária precisam ser reforçadas.

Palavras-chave: Pediatria. Odontopediatria. Cárie dentária. Saúde bucal.

Knowledge and attitudes of pediatricians in relation to dental caries.

Early dental care is emphasized today, since the attitudes and practices acquired during the first years of life become resistant to change. Because of greater contact with their patients, pediatricians are professionals of importance with regard to transmitting guidance relating to oral health. The present study had the aim of investigating the knowledge and attitudes of pediatricians practicing in Londrina, PR, regarding the promotion of oral health among the children that they attend. Data were collected by means of a questionnaire that covered matters relating to tooth formation and caries. Regarding dental caries, $28.8 \%$ of the pediatricians could not say what its etiology was, while $48.1 \%$ said that the disease was transmissible. The results observed suggested that the pediatricians presented positive attitudes and practices in relation to oral health, but that the information on dental caries needs to be reinforced.

Key words: Pediatrics. Pediatric dentistry. Dental caries. Oral health.

Conocimiento y actitudes de pediatras en relación a caries dental.

Actualmente ha sido enfatizada la atención odontológica precoz, pues actitudes y prácticas adquiridas en los primeros años de vida se resisten a los cambios. Debido al mayor contacto con sus pacientes el pediatra es profesional importante en la transmisión de orientaciones relacionadas a la salud bucal. El presente estudio tuvo el objetivo de verificar conocimiento y actitudes de médicos pediatras que ejercen en Londrina, estado de Paraná, Brasil, en relación a la promoción de la salud bucal de los niños que atienden. Los datos se recaudaron mediante cuestionario comprendiendo aspectos referentes a la formación de los dientes y de la dolencia de caries. Sobre la caries dental el $28,8 \%$ de los pediatras no informaron su etiología, mientras que el 48,1\% afirmaron el carácter transmisible de la enfermedad. Los resultados observados sugieren que los pediatras presentan actitudes y prácticas positivas en relación a la salud bucal pero que es necesario reforzar las informaciones sobre caries dentaria.

Palabras clave: Pediatría. Odonto-pediatría. Caries dentaria. Salud bucal. 